Nigerian Veterinary Journal 2010 Vol 31(1):26-36

\title{
ANIMAL HEALTH MANAGEMENT PERSPECTIVES OF RURAL LIVESTOCK FARMERS IN SOUTHWEST NIGERIA: THE PLACE OF COMMUNITY BASED ANIMAL HEALTH WORKERS
}

\author{
IDOWU, O. S. and BABALOBI, O.O*. \\ Department of Veterinary Public Health and Preventive Medicine, Faculty of Veterinary \\ Medicine, University of Ibadan, Nigeria. \\ *Corresponding author: Email: tayobabalobi@yahoo.com; Tel: +2348055301991
}

\begin{abstract}
SUMMARY
A case study of a typical community based rural livestock production system in South-west Nigeria was undertaken using participatory epizootiology (PE) to understand local preferences for animal health management practices and observe if there is any justification or place for community based animal health workers (CBAHW ) in rural livestock health and production management. Sheep and goats were the major animals kept by $46.7 \%$ of the respondents, followed by chicken $(29.3 \%)$, dogs $(13.3 \%)$, ducks $(8.0 \%)$ and pigs $(2.7 \%)$. The major health and production problems identified were Pestes des petit ruminants (PPR) $(30.0 \%$ of respondents), mange $(23.0 \%)$ and crop destruction $(20.0 \%)$; while cannibalism by hawks/eagle was the major problem of poultry production as highlighted by rural women $(15 \%)$. While more respondents $(42.7 \%)$ rate modern animal health practitioners as more effective than Fulani pastoralists healers $(33.67 \%)$ and indigenous local healers $(\mathbf{2 5 . 0 \%})$, modern animal health practitioners were described as least truthful/ unreliable $(91.7 \%)$, less available $(91.7 \%)$, most expensive $(66.7 \%)$ and inaccessible $(25.0 \%)$. On the other hand, indigenous local healers were rated as very available and more accessible $(66.7 \%)$ while Fulani pastoralist healers were rated as more available and ready to provide veterinary services $(\mathbf{5 8 . 3 \%})$ compared to indigenous local healers (33.3\%) and modern animal health practitioners $(8.3 \%)$. These results are similar to those obtained in other African countries. In conclusion, despite the prevailing professional apathy to the CBAHW concept by influential veterinary authorities in Nigeria, health issues highlighted by the community-based rural livestock farmers could be adequately addressed by CBAHW.
\end{abstract}

Key Words: Rural communities, Animal health, farmers' perspectives

\section{INTRODUCTION}

Participatory Epizootiology (PE) is the use of community-based participatory approaches and methods to collect detailed information, to improve the understanding of animal diseases and veterinary services, and to design solutions for disease problems with livestock keepers. For livestock health project intervention to be successful, it must be based 
upon intimate knowledge of local conditions obtained first hand, and at village level assessments (Johnston and Clark, 1982). Farmer participation in problem identification allows easier implementation and has a substantial cost-effectiveness (Farringnton and Martin, 1988). Although community participation has various meanings, the term in PE usually convey some form of interaction between local people and outsiders in which the former play a role in identifying, implementing or even controlling development activities. Overtime, participatory methods have attracted increasing interest from veterinarians and are now used by a wide range of organizations (Catley and Mariner 2002).

Although Community Health Workers (CHW) play recognized and acceptable significant role in the provision of human health services to rural communities in Nigeria (Asuzu 1993, 2004), the place of Community-Based Animal Health Workers (CBAHW) in similar animal health settings is still contentious and unrecognized in Nigeria. The propagation of the approved CBAHW ethos has been promoted by the African Union Inter-African Bureau for Animal Resources (AU-IBAR 2003), and supported by the World Animal Health Organization(OIE) and the Food and Agriculture Organization (FAO)- all three to which Nigeria is subscribed to. The Bureau define an Animal Health Worker as a person who performs a limited range of veterinary task as defined by the statutory body in a given country, to enable veterinary services to define lines of command and formal relationship (AU-IBAR 2003). Unlike in other East and Central African countries where there are legislative and gazetted recognition of the place of CBAHW (Sones and Catley, 2003), such is missing in Nigeria. This study applies a 'bottom-up' Participatory Research approach to: i. understanding local socio-economic perspectives and preferences of existing animal health management services of a community based livestock setting,

ii. determine what the livestock farmers in such setting consider to be the major constraints to animal health management and disease control in the study area

iii. verify if there is any justification and place for CBAHW in effective veterinary services, especially among the rural livestock farmers and

iv. assess the level of the involvement of rural livestock farmers in animal health management and development efforts relevant to them.

\section{MATERIALS AND METHOD Case Study}

Olohunde is a small village of about two hundred (200) inhabitants with thirty-two houses where free-range livestock keeping is an age long traditional practice for both men and women, and interest in livestock farming is relatively high. The village is located about five kilometers off Lanlate/Ado-Awaiye road in Ibarapa North Local Government area of Oyo State, Nigeria (Figure 1). The inhabitants of Olohunde are mainly Yoruba. The few non-indigenes living in the village are migrant farm laborers from neighboring Benin Republic. The major occupation for men in the village is farming and hunting; women engage mainly in trading in farm products apart from part-time subsistence farming. The active farming population is mainly within the age range of 35 to 55 years. Many of the younger people are either working or schooling in the cities and towns.

The study area was selected using convenient sampling because four out of the five-man multidisciplinary team, made up of two veterinarians, one crop scientist, one social worker, and one animal health extension 
worker were already familiar with the community, having been there as Christian development workers and missionaries under the Justice, Development and Peace Commission (JDPC) of the Ibadan Archdiocese of the Catholic Church.

\section{Materials}

A five-man multidisciplinary team (as described above) visited the village. All members of the team have some training and experience in participatory research. Apart from logistics (transport, stationeries, meeting venues, accommodation, food and honoraria) for the team, no other major inputs in terms of materials went into the implementation of this research, except the Participatory Research (PR) tools that were used for data collection and community participation. A 3.1 Mega pixels digital camera was also acquired to aid in recording pictures during the fieldwork.

The PR tools used for this project are: Focus Groups Semi-structured interviews (questions were asked, answers were freely given and friendly discussions were held, all participants were encouraged to contribute and analyze their contributions); other tools used include transect diagrams, seasonal calendars, historical matrices and matrix scoring.

Eighteen livestock farmers (eight women and ten men) actively participated in the meetings. There were two key informants for the PR. The PR team, guided by a small group of key informants and community people took a walk across the community, noting important features and undertaking informal discussions with community members on the issues generated by relevant observations made by team members in line with animal health and disease control in the community. The observations and discussions were represented graphically as transect diagrams, which were later discussed during semistructured interview sessions.

\section{RESULT AND DISCUSSION Livestock Species}

Using the livestock farmers' scoring, sheep and goats were the major animals kept by $46.7 \%$ of the respondents, followed by chicken (29.33\%), dogs (13.33\%), ducks $(8.0 \%)$ and pigs $(2.67 \%)$ (Table I). The criteria that determined why the species were kept were their importance:

i. as sources of income,

ii. sources of food, and

iii. importance of crop farming as source of animal feed (Table I).

\section{Source of income:}

Sheep and goats were kept by $41.01 \%$ followed by dogs $(25.64 \%)$, chicken $(20.5 \%)$, ducks (10.25\%) and pigs (2.56\%), as investments and readily available source of income in times of need by the rural livestock owners.

\section{Source of food}

Chickens were reared by $50.00 \%$ of the livestock farmers as handy and readily available source of food, followed by sheep and goat $(40.00 \%)$, with ducks providing the balance (10\%). Dogs and pigs were not reared as sources of food. Although some of them keep pigs, generally the people in Olohunde, being predominantly Muslims do not attach importance to pigs as a source of food. These reflect the cultural values and traditional farming systems in the predominantly Yoruba Southwest Nigeria and is similar to what Ademosun, (2004) and Adesehinwa et al. (2004) also found in similar Southwest Nigerian villages.

Importance of crop farming as source of animal feed

The ability of sheep and goat to natural graze on plants in the neighborhood makes their rearing easy at the community level. This was expressed by $68.75 \%$ of respondents. A 
lower figure $(25.0 \%)$ felt chicken were likewise easy to rear on plants and household wastes, while $6.25 \%$ hold this is applicable to pigs.

TABLE I: Matrix scoring of livestock species kept in Olohunde village.

\begin{tabular}{|c|c|c|c|c|c|c|}
\hline ITEM/CRITERIA & $\begin{array}{l}\text { SHEEP } \\
\text { AND } \\
\text { GOATS }\end{array}$ & CHICKEN & DOG & DUCK & PIG & TOTAL \\
\hline $\begin{array}{l}\text { Importance } \\
\text { Income source }\end{array}$ & $16(41.03 \%)$ & $8(20.5 \%))$ & $10(25.64 \%$ & $\begin{array}{l}4 \\
(10.25 \%)\end{array}$ & $1(2.56 \%)$ & $39(100 \%)$ \\
\hline Importance as Food & $8(40.00 \%)$ & $10(50.00 \%) 0$ & $(0.00 \%)$ & $\begin{array}{l}2 \\
(10.00 \%)\end{array}$ & $0(0.00 \%)$ & $20(100 \%)$ \\
\hline $\begin{array}{l}\text { Importance of Crop } \\
\text { farming as source of } \\
\text { animal feed }\end{array}$ & $11(68.75 \%)$ & $4(25.0 \%) 0)$ & $(0.00 \%$ & $0(0.00 \%)$ & $1(6.25 \%)$ & $16(100 \%)$ \\
\hline $\begin{array}{l}\text { TOTAL } \\
\text { LIVESTOCK }\end{array}$ & & & & & & \\
\hline $\begin{array}{l}\text { SPECIES } \\
\text { REARERS } \\
\end{array}$ & $35(46.67 \%)$ & $22(29.33 \%)$ & $10(13.33 \%)$ & $6(8.00 \%)$ & $2(2.67 \%)$ & $75(100 \%)$ \\
\hline
\end{tabular}

TABLE II: Ranking of animal health and public health issues by farmers in Olohunde village

\begin{tabular}{ll}
\hline ISSUES & SCORES \\
PPR & $30 \%$ \\
Mange & $23 \%$ \\
Crop Destruction & $20 \%$ \\
Cannibalism By Hawks And Eagle & $15 \%$ \\
Heavy Rains Aggravating Livestock Diseases & $12 \%$ \\
Total & $100 \%$ \\
\hline
\end{tabular}

TABLE III: Comparison of sources of animal health and disease control services

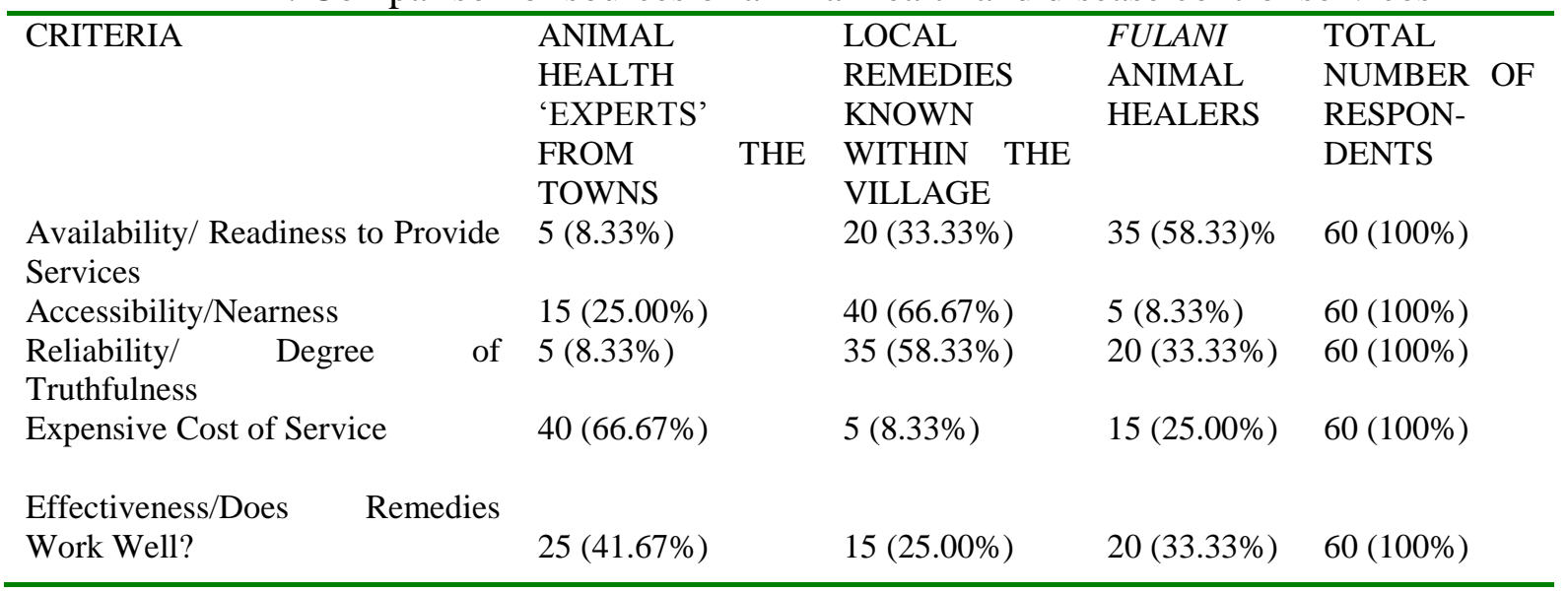




\section{Major Animal Diseases and Veterinary Public Health Issues}

Since sheep and goats are the most important livestock species kept by the farmers, the major diseases identified and discussed were mainly those that affect these species. Peste des Petite Ruminants (PPR) and Mange ranked $1^{\text {st }}$ $(30.00 \%)$ and $2^{\text {nd }}(23.00 \%)$ highest as scored by the farmers, while the tendency of goats and sheep to feed on crops planted around homesteads or nearby farms was listed as the $3^{\text {rd }}$ major problem by $20.00 \%$ of respondents (Table II).

The most important health problem discussed was referred to in their local Yoruba dialect as Ayohere. The PR team members had noted this problem too in their work in the village and have identified it as PPR. Farmers recounted the terrible losses in terms of mortality and loss of production recorded early in the year, as a result of the disease. The poor appearance of many sheep and goats seen around was also attributed to the PPR outbreak.

At the time that the PR was going on however, most of such animal houses were empty and animals were roaming freely around. It was explained that the recent PPR outbreak seemed to affect animals kept under intensive systems more than those kept on free-range, thus various owners decided to open their confinements. With this experience the villagers thought that confinement was a predisposing factor to PPR outbreak. A PPR vaccination campaign was reportedly held, where almost all goats and sheep in the village were brought by their owners for vaccination.

Other diseases and issues discussed include Mange (known as "Ekuku" in the local Yoruba dialect) and changes in the crop farming system in the village, whereby crop farms are now nearer the homes, making them accessible to livestock, thus resulting in animals especially goats destroying crops planted around homesteads. The issue of crop destruction forced many livestock owners to construct animal houses and keep their animals indoors.

Fifteen percent $(15 \%)$ of respondents, mainly livestock keeping women listed the problem of hawks and eagles cannibalizing on chickens. Also mentioned were the problems posed by heavy rains aggravating diseases in animals due to the attendant cold that predispose the animals to diseases.

When asked about the causative factors for PPR, which was ranked highest among the issues affecting livestock health and production, farmers mentioned such factors as confinement, poor feeding, poor hygiene, introduction of sick animals into the stock, transportation stress, other stress factors and exposure to cold conditions. It was only after asking a prompting question were they able to mention microbes as a factor.

On the possible treatment of the disease, farmers were unable to describe any particular treatment regimen, be it local or orthodox. Some farmers mentioned that they use some human medicines like Paracetamol $^{\circledR}$, Tetracycline and Flagyl ${ }^{\circledR}$, but no recovery was achieved in almost 
all cases. They mentioned that even the animal health experts called to help stop the outbreak failed to arrest the situation after collecting very high charges. Although they have been informed on the need of PPR vaccination as a preventive measure, the farmers still expressed some doubts on its efficacy.

Expectedly a few farmers believed that the outbreak was a spiritual attack and it can only be prevented and/ or treated by appropriately potent spiritual means.

The farmers' inability to describe any particular treatment regimen - local or orthodox- for PPR is uncharacteristic of communities where livestock production constitutes the traditional mainstay of livelihood. Over long periods, such farmers tend to find local (ethnoveterinary) remedies and management practices to manage the effects of serious diseases. However, a few mentioned an effective local remedy for retained placenta and fever in animals and a local remedy used against diarrhea and fever in humans, which proved effective when applied to sheep and goats showing similar clinical signs. This implies that the development and use of ethnoveterinary remedies is already in place and it will only take more time and commitment to animal health and further interactions with other cultures to have more effective remedies with low external (unsustainable) inputs.

\section{Comparison of Sources of Animal Health and Disease Control Services}

While more respondents $(42.7 \%)$ rate modern animal health practitioners as more effective than Fulani pastoralists healers $(33.67 \%)$ and indigenous local healers $(25.0 \%)$, modern animal health practitioners were described as least truthful/ unreliable (91.67\%), less available (91.67\%), most expensive $(66.7 \%)$ and inaccessible $(25.0 \%)$. On the other hand, indigenous local healers were rated as very available and more accessible $(66.7 \%)$ while Fulani pastoralist healers were rated as more available and ready to provide veterinary services $(58.3 \%)$ compared to indigenous local healers $(33.3 \%)$ and modern animal health practitioners (8.3\%) (Table III)

The percentage of farmers who scored animal health experts from nearby towns least truthful in their dealings $(91.67 \%)$ is particularly high. This was attributed to suppose sharp practices by these practitioners. It was alleged that these 'experts', including those from government agencies, most of the time have not provided satisfactory services and farmers are not getting value for their payments. The same percentage $(91.67 \%)$ considered animal health experts as non-available/not ready to provide required services, compared to the availability/readiness of itinerant Fulani animal healers $(58.33 \%)$ and the use of locally known remedies $(33.33 \%)$. Oladele-Bukola, (2004) has attributed poor delivery of animal health services in rural areas to similar reasons.

Although the findings are unique, it can be said that they are not a complete departure from what others have found from similar work on livestock health and production development in Southwest Nigeria, even when they often use more conventional veterinary research methods. The main animal species kept, the species used for food purposes, those not used for food (pig and $\operatorname{dog}$ ) and other findings are reflections of cultural values and traditional farming systems in the predominantly Yoruba Southwest 


\section{Idowu et al: Animal health perspectives and preferences of rural livestock farmers}

Nigeria and is similar to what Ademosun, (2004) also found in a similar Southwest Nigerian village. The problem of PPR and Mange is typical of reports in other communities where goats constitute a good majority of animals kept (Ademosun, 2004).

The factors relating to PPR epizootiology mentioned by the farmers to include microbes, confinement, poor feeding, poor hygiene, and introduction of sick animals into the stock, transport (and other stress) and exposure to cold conditions; and that PPR is an acute disease, affecting goats more than sheep, affecting all ages with higher and rapid mortality rates among younger stock and those in confinement, are almost the same as those stated by Ademosun, (2004).

\section{The Place of Community Animal Health Workers}

The animal health issues raised by respondents- PPR, Mange, Rainy season mortalities, Hawk cannibalism-are issues which can be handled by CAHWs through effective veterinary extension education and delivery to the rural livestock farmers. The perception of 'animal health experts' from government services in nearby towns as least truthful in their dealings, providing unsatisfactory services and farmers are not getting value for their payments, compared for example with itinerant pastoralist Fulani animal healers and the use of locally known remedies, are important issues that will enhance the acceptability of CAHW.

Similar studies on the place of CBAHW have been done in other African countries (e.g. Mugunieri et al., 2002, in a study in a Kenyan region)
By using existing traditional knowledge, CBAHW programs encourage the participation of the local communities in the design and delivery of animal health care services. The CBAHW model also empowers the local people to determine the type of animal health services they receive. This community-based approach has shown that pastoralists and agro pastoralists, for example, can organize themselves to select CBAHW for training and offer animal health services. Factors found to significantly influence the performance of the CBAHW included those capturing recent participation in professional development courses, proximity to roads and retail service and input outlets, and non-farming income. The results point to support for CBAHW as a low-cost and sustainable strategy. However, supportive institutional and legal frameworks, which are currently lacking in most African countries, should first be developed (Sones and Catley, 2003).

There has been an increasing consensus that CBAHWs or their equivalent can play a significant role in the delivery of veterinary services under certain circumstances where conventional veterinary systems cannot operate. CBAHWs by the nature of their background, may have limited education and so require careful supervision and strict restrictions on the veterinary tasks that they can carry out e.g. simple treatments, administration of vaccines etc. The development of the role of CBAHWs in veterinary services has been greatest in East Africa, but auxiliaries are also widely employed by veterinary services in certain West African countries. The Pan African Program for the Control of Epizootics (PACE) has ensued the development of 
national guidelines for Community based Animal Health workers (CAHW) systems, legislative reform, development of licensing procedures for CAHW trainers and trainees, development of agreements with implementing agencies to ensure harmonised approaches and private sector involvement (Booklet on PACE Success Stories).

The Pan African Program for the Control of Epizootics (PACE) had a Community-based Animal Health and Participatory Epidemiology (CAPE) unit (www.cape-ibar.org), which involve disseminating experiences in participatory epizootiology via academic and informal publications, training of senior-level Epizootiologists in government veterinary services, veterinary schools and research institutes, and applying participatory approaches in the field. CAPE also encourages veterinary schools to explore options for incorporating community based animal health and participatory epidemiology into undergraduate and postgraduate curricular; and also support postgraduates to conduct participatory research in pastoral areas.

In Nigeria, as espoused by the AUIBAR/PACE Community-based Animal Health and Participatory Epidemiology CAPE Unit (www.cape-ibar.org) and the Institutional and Policy Support Team (IPST), its 2005- 2010 successor (http://www.eldis.org/pastoralism/cape/i ndex.htm), at the Department of Veterinary Public Health and Preventive Medicine, Faculty of Veterinary Medicine, University of Ibadan, community-based animal health and Participatory Epizootiology have been incorporated into undergraduate and postgraduate curricula and postgraduate students have been supervised to conduct participatory research in livestock keeping communities of southwestern Nigeria (Idowu 2005, Ogunwale 2007). It is expected that other veterinary schools in Nigeria will adopt this paradigm (Babalobi and Idowu,2005)

\section{RECOMMENDATIONS CONCLUSION}

1. The place of CBAHW in the provision of veterinary services to community based rural livestock farmers should be officially recognized by veterinary authorities in Nigeria. Relevant legislative changes should be put in place accordingly.

2. Participatory Research Epizootiology should be promoted and taught at undergraduate and postgraduate levels, to enhance proper understanding of livestock farmers.

3. The principles, practices and privatisation of the CBAH system developed by PACE and espoused by the Community-based Animal Health and Participatory Epidemiology (CAPE) unit of the Pan African Control of Epizootics (PACE) should be heartily implemented in Nigeria, as it is in East, Central and parts of West Africa.

4. The role of Veterinary Technicians (Diploma holders in Veterinary Science) in the provision of veterinary services in Nigeria should be reviewed and given relevant place. This could include a review of their curricular, and placement of their professional certification under a relevant unit of the Veterinary Council of Nigeria, rather than the present 
certification by the non-veterinary National Board for Technical Education. The misnomer of referring to them as 'quacks' should be discouraged.

5. The use of the FOOD AND AGRICULTURE

ORGANIZATION OF THE UNITED NATIONS (FAO) MANUAL ON PRIMARY ANIMAL HEALTHCARE WORKER, ROME 1994 (http://www.fao.org/docrep/t069 $\underline{0 \mathrm{e} /})$, in the training of community based animal health workers in different parts of Nigeria in basic primary animal healthcare should commence and be facilitated; following the African Union/InterAfrican Bureau for Animal Resources Policy on Community Animal Health Workers (http://www.eldis.org/fulltext/cap e_new/PolicystatementCAHWs.p df)"

With such measures above, a more appropriate and sustainable livestock health and production development approaches of rural livestock farmers and pastoralists who constitute the majority livestock holders will be enhanced.

\section{REFERENCES}

ADEMOSUN, A. A. (2004): Constraints and Prospects for Small Ruminants Research and Development in Africa. Livestock Research for Rural Development, 16 (8). 27-32.
AU-IBAR
(2003):
AFRICAN UNION/INTERAFRICAN BUREAU
FOR
ANIMAL

RESOURCES. POLICY ON COMMUNITY-BASED

ANIMAL HEALTH WORKERS (2003). 2pp

ASUZU, M.C. (1993): CommunityBased Medical Education: A Review of the Oldest Programme in Nigeria. Annals of Community-Oriented Education. 6:69-81.

ASUZU, M.C. (2004): Modern Paradigms in Medical and Health Sciences Education: Wither Ibadan? University of Ibadan Postgraduate School Interdisciplinary Discourse. 60pp.

BABALOBI, O.O. and IDOWU O. (2005). The Paradigm of Community-Based Participatory Epizootiology: A Review. Tropical Veterinarian. Vol. 23 (3\&4) 69-77.

CATLEY, A and MARINER J (2002): $\mathrm{W} h$ ere there is no data: Participatory approaches to veterinary epidemiology in pastoral areas of the Horn of Africa. Issue paper No 110.

FARRINGTON, J. and MARTIN, A. (1988): Farmer participation in agricultural research: A Review of concepts and practices. Agricultural Administration. Occasional paper, No. 9, Overseas Development Institute, London.

IDOWU O.S. (2005): Participatory Epizootiology: Research for Animal Health and Production 
Development in Olohunde Village, Lanlate, Oyo State, Nigeria. A Masters of Preventive Veterinary Medicine (MPVM) degree Project in the Department of Veterinary Public Health and Preventive Medicine, Faculty of Veterinary Medicine, University of Ibadan, Ibadan, Nigeria. 66 pp.

JOHNSTON, B., and W. CLARK. 1982. "Organization Programs: Institutional Structures and Managerial Procedures." In Redesigning Rural Development: A Strategic Perspective. Baltimore, Md.: Johns Hopkins University Press.

MUGUNIERI L.G., OMITI J.M. and IRUNGU P. (2002): Animal Health Service Delivery Systems in Kenya's Marginal Areas under Market Liberalization: A Case for Community-Based Animal Health Workers Policy Brief 2 November 20022020 VISION NETWORK FOR EAST AFRICA International Food Policy Research Institute. $2033 \mathrm{~K}$ Street, NW. Washington, DC 20006-1002 USA. http://www.ifpri.org/2020/nw/rep ort/2020nw_rp03.pdf

Accessed 13 ${ }^{\text {th }}$ March 2010

OGUNWALE, C. I. (2007): Participatory Appraisal of Livestock Diseases with Livestock Keeping Women of Awotan, Ido LGA, Oyo State, Nigeria. A Research Project Report submitted to the Department of Veterinary Public
Health and Preventive Medicine, Faculty of Veterinary Medicine, University of Ibadan, Nigeria, in partial fulfillment of requirements for the award of the degree of Master of Veterinary Public Health (MVPH).

OLADELE-BUKOLA, M.O. (2004):

The Prevalence, Seasonal and Socio-Economic Importance of Bovine Fascioliasis at Ibadan Municipal Abattoir (1994-2004). MVPH Project, University of Ibadan, Nigeria.

SONES, K. R. AND CATLEY, A. (Eds) (2003): Primary Animal Health Care in the 21st Century: Shaping the Rules, Policies and Institutions. Proceedings of an international conference held in Mombasa, Kenya, 15-18 October 2002. African Union/InterAfrican Bureau for Animal Resources, Nairobi, Kenya. Pp 9 -10

USAID MISSION IN ABUJA FCT (2004): Animal Health Priorities in

Nigeria http://www.usaid.gov/ng/abuja.ht $\underline{\mathrm{m}}$

www.au-

ibar.org/ach_animhealth/PACE \%20Booklet.pdf

www.cape-ibar.org

\section{SUPPORTING NOTES}

Booklet on PACE Success Stories

http://www.eldis.org/pastoralism/cape/in dex.htm

http://www.vetwork.org.uk/cahcah.htm. 
Idowu et al: Animal health perspectives and preferences of rural livestock farmers

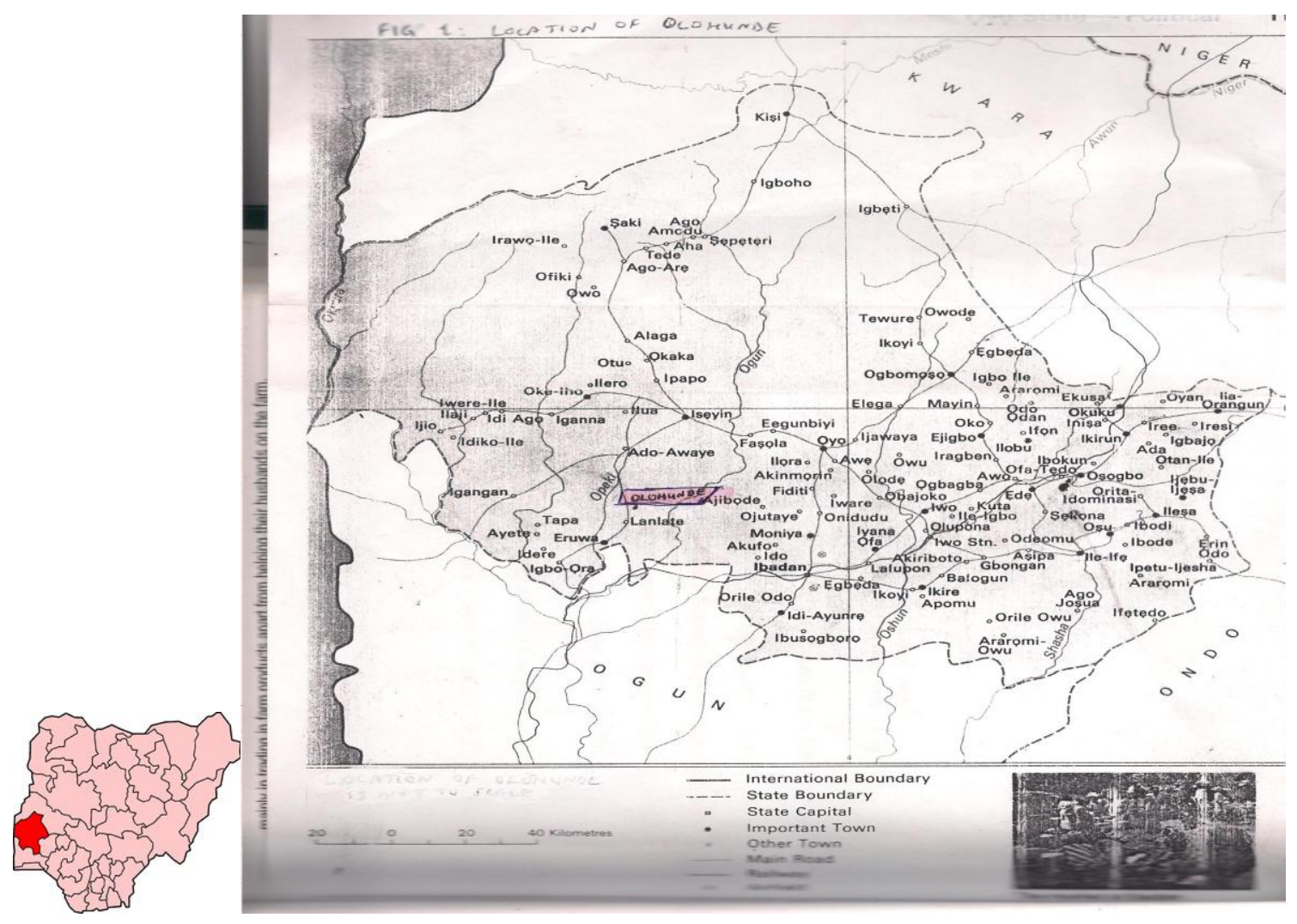

